\title{
Eastern and Western Children's Voices on their Well-Being
}

\author{
Silvia Exenberger ${ }^{1}$ (D) Raphaela Banzer $^{2}$ • \\ Jayakumar Christy $^{3}$ - Stefan Höfer ${ }^{1}$ - Barbara Juen ${ }^{2}$
}

Accepted: 31 January 2018 / Published online: 22 February 2018

(C) The Author(s) 2018. This article is an open access publication

\begin{abstract}
Few studies are planned to 'give voice' to children from different cultural backgrounds to explore their sources of happiness. To address this gap, the present study analysed focus group discussions with 42 South Indian and 48 European children aged 8 to 17 years. During the discussions, the children were asked about what makes them happy and sad and about what helps them feel good again when they feel sad. The data were analysed based on grounded theory. Data analysis revealed the following seven themes: 'Indian and European children attach different values to school', 'interactions with biological families both support and threaten well-being', 'positive and negative effects of relationships on the self', 'Indian and European children name different exclusive well-being sources', 'cross-cultural and culture-specific coping and relaxation strategies', 'staying physically healthy is important to the children's wellbeing', and 'material and economic resources are clearly linked with children's wellbeing'. Moreover, the results suggest that the meaning of the well-being themes is shaped by a child's self-construal, which is either independent (the self is separated from others) or interdependent (the self is connected with others). How culture might influence children's viewpoints regarding their own well-being is discussed.
\end{abstract}

Keywords Subjective well-being $\cdot$ Happiness $\cdot$ Children $\cdot$ Culture $\cdot$ Giving voice

Silvia Exenberger

silvia.exenberger-vanham@i-med.ac.at

1 Department of Medical Psychology, Medical University of Innsbruck, Speckbacherstr, 23/3, 6020 Innsbruck, Austria

2 Department of Psychology, University of Innsbruck, Bruno-Sander-Haus, Innrain 52f, 6020 Innsbruck, Austria

3 Department of Psychiatric Social Work, National Institute of Mental Health and Neurosciences (NIMHANS), Bengaluru, Karnataka 560029, India 


\section{Introduction}

'Happiness' is sometimes disguised behind the scientific term 'subjective well-being' (SWB), although the terms are often used interchangeably (Deci and Ryan 2008; Diener and Napa Scollon 2014; Lu 2001; Tov and Diener 2013). Aristippus, a Greek philosopher from the fourth century B.C., equated well-being with hedonic pleasure or happiness. His theory taught that the experience of pleasure is the highest good and a proper aim in human life (Ryan and Deci 2001). The counterpart to Aristippus' hedonic approach to well-being is Aristotle's eudaimonic one (ibid.). Aristotle described eudaimonia as the "... highest of all human goods as the realisation of one's true potential” (Ryff and Singer 1998, p. 2). Both philosophical approaches are key elements of Rees et al.'s (2013) framework of self-reported well-being. This framework divides well-being into a hedonic or SWB component and a eudaimonic or psychological well-being component. The hedonic path of well-being focuses on the study of positive emotions and life satisfaction (Diener 1984), whereas psychological well-being arises from the eudaimonic well-being tradition (Rees et al. 2013) and comprises such aspects of Ryff's (1989) well-being model as self-acceptance, positive relationships with others, and autonomy. Different scholars have criticised the current literature on happiness and well-being because both well-being traditions are rooted in Western streams of thought, while Eastern conceptions are rather neglected (Joshanloo 2014). To address these drawbacks, Joshanloo (2014) compared Eastern and Western schools of thought on happiness and well-being. He identified six fundamental differences in the conceptualisations of a good life. These differences included the grouping of the poles of eudaimonia and hedonism, which represent an Eastern and a Western concept of happiness, respectively. However, both approaches can be found to a certain extent as a way of pursuing happiness in both cultures. Throughout history, philosophers and thinkers from various cultures have discussed conceptualisations of happiness (as shown in the review of Joshanloo 2014), whereas the thoughts of lay people regarding their meaning when they speak about happiness have been comparatively neglected (Delle Fave et al. 2011). The present study aimed to examine children's sources of happiness and to determine the meanings children attribute to their sources of wellbeing.

In the field of SWB, weight is given to people's own perception of their life, i.e., how people appraise their life in thoughts and feelings. Similarly, children's SWB comprises children's self-evaluations of their lives, including their cognitive judgements regarding life satisfaction and its domains of school, family, community, and interpersonal relationships as well as affective evaluations such as moods and emotions (Huebner 2004; Newland et al. 2015). "Thus, a person is said to have high SWB if she or he experiences life satisfaction and frequent joy and only infrequently experiences unpleasant emotions, such as sadness and anger. Contrariwise, a person is said to have low SWB if he or she is dissatisfied with life, experiences little joy and affection, and frequently feels negative emotions, such as anger or anxiety" (Diener et al. 1997, p. 25). Different authors have found that people, irrespective of their culture, are likely to prefer the desirable over the undesirable and the pleasant over the unpleasant (Diener et al. 1995) or to consider happiness a pleasant inner state of mind ( $\mathrm{Lu}$ and Gilmour 2004). However, what constitutes a good and valuable life varies across cultures (Diener and Suh 2000). Although scholars agree that culture has a key influence on how people perceive and 
construct 'happiness' (e.g., Lu and Gilmour 2006; Uchida et al. 2004; White 2008), most instruments investigating happiness or SWB are based on Diener et al.'s (1997) definition, which originates from a Western stream of thought (Delle Fave et al. 2011). To overcome this shortcoming, Delle Fave et al. (2011) suggest a qualitative approach with diverse cultural samples to conceive cross-cultural meanings of happiness. Starting from the premise that cultural values can be a major force in determining the conception of happiness or SWB, the present study had the goal of exploring the qualitative aspects of what constitutes happiness from the perspective of children from a Western (European) or Eastern (Indian) cultural background.

\section{Child Well-Being Indicators}

O'Hare (2012) defines child well-being indicators as “... statistics that provide a sense of whether a group of children enjoy a good quality of life" (p. 79). The research field of child well-being indicators originated from the so-called social indicators movement of the 1960s and 1970s (Ben-Arieh 2008, 2010), with its basic question, 'How are we doing?'. This question was adapted for children as 'How are our kids (including adolescents and youths) doing?' (Land et al. 2011). The obtained answers provided a way to describe the condition of children, monitor or track child outcomes and set goals (ibid.).

Over time, research concerning the state of children has undergone several changes, as noted by Ben-Arieh (2008, 2010). From these major shifts, Fernandes et al. (2012) highlighted the following three trends in their review of child well-being measurements: (1) 'child-centred focus', in which the child moves to the centre of attention and becomes the unit of analysis; (2) 'multi-dimensionality' means that child well-being cannot be derived solely from one dimension of life, such as family income, but needs to comprise multiple dimensions that affect a child's life; and (3) 'reliance on composite child well-being indices' implies the aggregation of indicators into a single composite child well-being index.

A rather new development regarding various dimensions of well-being (the second trend in child well-being research, as mentioned above) is the introduction of SWB. Ben-Arieh (2005) claims that attempts to understand children's well-being should be grounded in the children's own experiences and perspectives, i.e., the children should occupy the role of active participants rather than the subjects of research. Although several studies on children (e.g., Bradshaw et al. 2007) have added the aspect of SWB to their indices, the International Survey of Children's Well-Being (ISCWeB) (http://www.isciweb.org) is a unique research project. It is a world-wide survey of child SWB that is based solely on the children's own evaluations, perceptions, and aspirations in different life domains (Dinisman et al. 2015).

\section{Child Informants and Culture}

In addition to Ben-Arieh's (2005) demand that children themselves should evaluate their lives, he postulates that relevant indicators can only be developed on the basis of the children's own experience. In general, Boyden and Ennew (1997) emphasised the 
importance of children's participation in child research. The authors defined "participation in the sense of knowing that one's actions are taken note of and may be acted upon ..." (Boyden and Ennew 1997, p. 33). he claim that children's voices should be heard is grounded in the fourth category of rights in the United Nations Convention on the Rights of the Child (CRC). This category comprises the participation rights of children (UNICEF, n.d.), which means that children have an active voice. Article 12 (Respect for the views of the child) emphasises that children's opinions need to be taken into account when adults are making decisions that affect them (UNICEF, n.d.). This means that children know what is important to them, and as a result, they know what is important to know about their lives. Furthermore, Ben-Arieh (2005) argues that child well-being indicators that are not, at least in part, gained from interactions with children cannot claim to be based on CRC. In this vein, Fattore et al. (2007, 2009) explored the views of Australian children on the meaning of well-being and its relationship to their everyday experiences. Based on the children's statements, the authors developed a set of well-being indicators for monitoring children's well-being over time. Gabhainn and Sixsmith (2005) pursued the same goal as Fattore et al. (2007, 2009) and elaborated a national set of child well-being indicators in Ireland that was partly grounded on the photographs that children took of things, people, and places that 'make them well' or 'keep them well'. In contrast to the ambitious goals for developing national sets of child indicators, Andresen and Fegter's (2011) study aimed to gain insight into a specific group of children's views on what constitutes a good life for all children. Children living in poverty in Germany were asked to identify the conditions of a good life. In general, researchers increasingly follow this participatory trend and involve children in the entire research process or parts thereof. Without claiming completeness, Dex and Hollingworth (2012) show this trend in their literature review regarding child informants. They identified $11 \mathrm{UK}$ studies and nine non-UK studies that researched what children understand about their well-being in general. Interestingly, none of the non-UK studies included in this literature review was conducted with non-Western child samples. In fact, literature regarding children's experience and understandings of well-being through participatory research in non-Western countries is scarce compared with this kind of research in adult samples (Camfield et al. 2008). Based on qualitative research on well-being with samples of adults from different cultural backgrounds, it is well documented that happiness as a state of mind may be universal, but its meaning takes culture-specific forms (Uchida et al. 2004). Several studies that questioned adults with different cultural backgrounds (e.g., Caucasian American vs. Southern Taiwan: Lu and Gilmour 2004, German vs. South African: Pflug 2009) about their definition and sources of happiness have shown a clear influence of individualism and collectivism (Triandis 1995) on people's lay theories about happiness. Specifically, in collectivistic cultures, in which the relatedness is emphasised, the key terms associated with happiness were harmony and role obligations, whereas in individualistic cultures, in which independence is of great importance, individual agency and explicit pursuit of happiness were dominant values (Pflug 2009). According to Suh (2000), the self holds a key to untangling the complex relationship between culture and SWB, as the self stands at the junction of these two concepts. How the self - which is formed and shaped by culture - influences what individuals feel and think about various aspects of their lives (Suh 2000) has also been shown in studies with children. In their explorative study, Wilmes and Andresen (2015) compared the 
well-being of children in different environments to determine what a good childhood means to Nepali children and whether their concept of childhood differs from that of children in Germany. The analysis exposed the limitations of research instruments based on a Western approach and a Western idea of childhood. For example, the dominance of a Western approach to childhood is clearly reflected in the domain 'time use' because the items are based on Western ideas regarding how children spend their time. In Nepal, leisure time is rarely institutionalised, and spending time with the family is very important in children's everyday life. The authors concluded that scholars in the child well-being research field do not have sufficient knowledge about children's views of a good life in non-Western countries.

To further elucidate the influence of culture on children's own view of their wellbeing, the current study questioned children from two very different cultural backgrounds (Europe vs. South India). The European children from Austria and Germany grew up in an individualistic environment. The South Indian children grew up in highly collectivistic surroundings, i.e., small, single-caste fishing hamlets. One main feature of the villages' political system is decentralisation (Bavinck 2008), which serves as the basis for a hierarchical collectivistic lifestyle (Triandis 1995). Each village is ruled by a so-called 'uur panchayat', which is the internal governance structure of a fishing community and possesses a large degree of authority and power. Uur panchayat leaders also represent the village as a whole to the outside world. This practice ensures that fishers rally around their uur panchayats and work as a collective. Moreover, decentralisation isolates these small fishing villages from the main body of Tamil society (Bavinck 2008). For children's everyday lives, growing up in such a highly collectivistic surrounding (so-called 'vertical collectivism' according to Triandis 1995) means full approval of authorities, unquestioning respect towards adults, obedience, duty and reliability (Triandis 1995).

The main purpose of the present investigation was to explore the sources of happiness among children with different cultural backgrounds. The explicit aims were (1) to give children the voice to formulate in their own words what constitutes happiness for them and (2) to identify similarities and differences in the views of happiness among European and South Indian children. The aim was not to determine the children's views of their well-being with respect to living apart from their biological families or being put into care. Priority was given to the cultural comparison of children's perceptions of what constitutes well-being and was based on groups of children who live in similar micro-environments.

\section{Method}

\subsection{Setting}

The children came either from Austria, Germany or South India. The German children came exclusively from Southern Germany, which borders Austria. Due to this geographical and cultural proximity, the German and Austrian children were pooled to create the European sample.

All the participating children lived in family-based out-of-home care. The Austrian and Indian children lived in SOS Children's Villages, which is an independent non- 
governmental and social development organisation that operates worldwide in 134 countries and territories (SOS Children's Villages: A general overview n.d.., para. 7). The organisation focuses on children who have lost parental care or are at risk of losing it. Each child lives with a social parent (SOS mother) and social and/or biological siblings in a house within an SOS village. An SOS village consists of approximately ten family houses (SOS Children's Villages: A general overview, n.d.). The German children's main place of residence was the Caritas-Kinderdorf Irschenberg, a Christianorientated organisation located in Southern Germany in which children and youth live in 'Kinderdorf' families. One family shares a house, and several houses constitute a 'Kinderdorf' village (Caritas Kinderdorf Irschenberg, n.d.).

\subsection{Participants}

A total of 90 children participated in the study. Approximately half of the children $(N=$ 48) composed the European sample. The European children lived in out-of-home care because it was no longer in their best interest to stay with their parents. The only criterion for their participation in the study was an age of 8 to 17 years. Most of the children had experienced some type of trauma in their life (e.g., domestic violence, parental substance abuse). The second half of the children $(N=42)$, who composed the Indian sample, were affected by the 2004 Tsunami. They lived in out-of-home care because they had lost either their mother, father or both to this disaster. Eligibility criteria for the Indian children were age 8 to 17 years, direct exposure to the Tsunami, and Hindu religion. It should be noted here that the Indian children had all experienced comparable trauma (the Tsunami), whereas the European children had not.

The complete sample included 46 boys (29 European boys, 17 Indian boys) and 44 girls (19 European girls, 25 Indian girls). At both research sites, the children were divided into two same-sex age groups: 'older girls/boys' (12 to 17 years) and 'younger girls/boys' (8 to 11 years). The first author recruited the Indian children, and the second author recruited the European children. The present study was part of a large, funded research project that was implemented four years post-disaster (for more information, see Exenberger and Juen 2014).

Table 1 gives an overview of the demographic characteristics of the children.

\subsection{Focus Group Discussions}

To obtain each child's understanding of well-being and ill-being, Vogl's (2005) qualitative method of focus group discussion for children was employed. Group discussions

Table 1 Demographic characteristics of children participating in the focus groups according to age, sex and location

\begin{tabular}{|c|c|c|c|c|c|c|c|}
\hline sex & $\begin{array}{l}\text { Younger age } \\
\text { group: SOS } \\
\text { CV India }\end{array}$ & $\begin{array}{l}\text { Older age } \\
\text { group: SOS } \\
\text { CV India }\end{array}$ & $\begin{array}{l}\text { Younger age } \\
\text { group: SOS } \\
\text { CV Austria }\end{array}$ & $\begin{array}{l}\text { Older age } \\
\text { group: SOS } \\
\text { CV Austria }\end{array}$ & $\begin{array}{l}\text { Younger age } \\
\text { group: CV } \\
\text { Germany }\end{array}$ & $\begin{array}{l}\text { Older age } \\
\text { group: CV } \\
\text { Germany }\end{array}$ & Total \\
\hline Female & 12 & 13 & 5 & 5 & 4 & 5 & 44 \\
\hline \multirow[t]{2}{*}{ Male } & 11 & 6 & 8 & 12 & 4 & 5 & 46 \\
\hline & 23 & 19 & 13 & 17 & 8 & 10 & 90 \\
\hline
\end{tabular}


should take place mainly between the respondents and be facilitated by the researcher, whose role is to ensure that the topics are adequately covered and that all group members have an equal chance to talk (Boyden and Ennew 1997). In the present study, up to ten children were gathered in same-sex and same-age groups, and they answered the following main questions:

- What (in general) gives you happiness? What makes you happy or feel good?

- What makes you feel sad or not good?

- If you feel sad or not good, what helps you feel good again?

The first question addressed sources of children's happiness. The second question focused on 'the other side of the coin', on the children's sources of sadness or not feeling good, i.e., on children's ill-being. Both questions were based on Fattore et al.'s (2007) study findings with Australian children, which revealed the children's own definition of well-being, including both positive and negative well-being features. With the term "well-being", children associated "positive feeling states such as happiness, excitement and peacefulness or calm, some children included being able to integrate anger and sadness into their lives as part of well-being" (Fattore et al. 2007, p. 17). This definition of well-being is to some extent distinctive of individualistic cultures because the 'expression of negative emotions' such as anger and frustration, which are considered 'ego-focused emotions', is more frequent among those belonging to such cultures (Markus and Kitayama 1991). Nevertheless, in the present study, the children were asked about their well-being and ill-being, as the two constructs are interdependent: without happiness, unhappiness will not be distressing, and without unhappiness, happiness will not be precious ( $\mathrm{Lu} \mathrm{2001).} \mathrm{According} \mathrm{to} \mathrm{Lu} \mathrm{(2001),} \mathrm{the} \mathrm{generally}$ abstract and illusive conceptions of happiness become more graspable and comprehensible when individuals are asked about the causes of happiness. These two broad questions were supported with further questions for clarification and by asking the children for examples from their everyday lives. We consciously did not ask more precise questions about specific well-being themes because we did not want to give the children ideas about what might constitute their well-being; instead, we aimed for the children to inspire each other when they discussed the topic in small groups and subsequently in the plenum. There were two reasons for including the third question (coping) as a closing question in the focus group discussion process. First, we started from the premise based on Lu's (2001) research that happiness and unhappiness are intertwined and that each depends on the other for contrast and meaning. This implies that happiness and unhappiness are conflictual but can transform and integrate at a higher level. With the question about coping strategies, we attempted to ask about the children's ability to transform from an unhappy state to a happy state. Second, the inclusion of this question gave the children the chance to experience that they are not the only ones who feel bad.

\subsection{Procedure}

For the work with the Indian sample, a male and a female university student from the same culture were trained in the study's objectives. They were bilingual in Tamil and English and provided interpretation in same-sex groups for the entire research process. 
These two students acted as both interpreters and cultural intermediaries, linking groups or persons of different cultural backgrounds to facilitate collaboration. They were trained for their task as interpreters and culture-brokers at the same time by the first author (for a detailed description on how to work with interpreters in a culture-sensitive environment, see Exenberger 2013). The second author conducted the focus groups with the European sample by herself.

The children's caregivers gave written and oral consent for the children's participation. A child-friendly version of informed consent was given to the children, who gave their oral consent. At any stage of the research process, the children could refuse to participate. No child asked to leave the group.

All focus group discussions began with an introduction game. The 'happy' and 'sad' topics were each introduced with a visual stimulus (a picture of children playing happily and a picture of a sad-looking boy, respectively). After the children had identified both topics of the visual stimuli, they discussed each topic in small groups and then shared their results in the plenum. For the last question, the children were asked to use modelling clay or coloured markers and paper to create a symbol of a coping strategy that they use to come out of a sad or unhappy mood. Their symbols were discussed in the group. After each topic, a game was played. At the end of the focus group discussions, we provided drinks and snacks to ensure that the children left the sessions in a happy mood. During snack time, the children had the opportunity to ask questions or to just chat. If a child became upset during the research process, we helped the child to come out of his or her sad mood. Moreover, the first author was available for the South Indian children up to two years after the questioning because she lived in South India and visited the SOS Children's Villages on a regular basis. The second author gave her email address to the children and caregivers so that they could contact her after she had left. In general, all SOS children, irrespective of their culture or country, have the opportunity to consult the psychologist or educationalist of SOS Children's Villages according to their needs.

All the focus groups were audio-taped. The group discussions took up to two hours due to the involvement of play elements and working with different stimulating materials. Seven focus groups were implemented with the European sample and five with the Indian sample. All focus groups in Austria and Germany were conducted from May to July 2011; those in India were conducted from February to April 2009. The cultural adequacy of the implementation process used with the Indian groups was guaranteed by the Indian supervisor of the cooperating partner, the National Institute of Mental Health and Neurosciences (NIMHANS). The ethics committee of the funding agency approved the study.

\subsection{Data Preparation and Analysis}

The Tamil portions of the recorded focus group discussions were translated into English by the university students. All the transcribed interviews (English and German) were analysed based on grounded theory (Corbin and Strauss 2008; Glaser and Strauss 1967). This approach investigates 'actualities' in the real world and analyses data with no preconceived hypothesis. As a first step, words and phrases of the interviewees that highlight an issue of importance or interest to the research are noted. Notes are generated and organised manually; for each descriptor, phrase codes are assigned, 
and similarly, codes are grouped into so-called concepts (Corbin and Strauss 2008). In the present research, concepts were renamed as subcategories. These subcategories were then grouped and regrouped to identify higher order commonalities called categories using the constant comparative method (Glaser and Strauss 1967), in which each subcategory is repeatedly compared to all other subcategories to form even broader categories. At a very high and abstract level of analysis, categories are bundled into core categories, which are called 'domains' in this study. At the most abstract level of the analysis - the core category - it is possible to go back (within the data pool) to the most basic group of data - the codes, which reflect the interviewees' original phrases.

\section{Results}

The analysis of the Indian children's focus group discussions resulted in the identification of five distinct domains (physical, psychological, cognitive, social, and economic), 11 categories and 34 subcategories (Exenberger and Juen 2014). Within the European sample, the same five domains as within the Indian sample were identified, along with ten categories and 32 subcategories. These five domains support the findings of Pollard and Lee's (2003) systematic review of the literature on child wellbeing. All the domains consisted of positive and negative indicators referring to the children's well-being and ill-being, respectively. Table 2 shows the domains, categories and subcategories of the Indian sample compared with those of the European sample.

In the following, we will give an overview of each of the domains and their associated categories and compare the two samples.

\subsection{Cognitive Domain}

The cognitive domain included topics such as a child's integration into school and themes that were considered intellectual or school-related in nature.

\subsubsection{Indian and European Children Attach Different Values to School (Category: Academic)}

Indian Children The children discussed the importance of attending school on a regular basis for their future life. Attending school was not something to be taken for granted before the Tsunami due to the substantial work burden at home. The children greatly appreciated the school education they received because it would enable them to choose different professional paths. Being able to pursue a career gave them a positive outlook for their future and mitigated their sorrows. Moreover, a steady job in the future would allow them to take care of relatives who cared for them after the Tsunami. Scoring good marks in school was of great importance to the Indian children and a definite source of happiness because it brought them a step closer to their future aims. Lower grades threatened their optimism about the future and were a source of ill-being. However, the Indian children were distinctly aware of their advantage in receiving a good school education considering that many children in India do not have this chance. As some children put it: "Studying well is good for us and also for my mom [SOS 
Table 2 Domains, categories, and subcategories of the Indian sample compared with the European sample

\begin{tabular}{|c|c|c|c|c|}
\hline \multirow{2}{*}{ Domain } & \multicolumn{2}{|l|}{ Indian sample } & \multicolumn{2}{|l|}{ European sample } \\
\hline & Category & Subcategory & Category & Subcategory \\
\hline \multirow[t]{3}{*}{ Cognitive } & \multirow[t]{3}{*}{ Academic } & School $(+/-)$ & \multirow[t]{3}{*}{ Academic } & School (+/-) \\
\hline & & Future perspectives $(+)$ & & Off school $(+)$ \\
\hline & & Arts $(+)$ & & \\
\hline \multirow[t]{23}{*}{ Social } & \multirow[t]{6}{*}{$\begin{array}{l}\text { Interactions with } \\
\text { biological family \& } \\
\text { caregivers }\end{array}$} & $\begin{array}{l}\text { Family-based out-of- } \\
\text { home care }(+/-)\end{array}$ & \multirow[t]{6}{*}{$\begin{array}{l}\text { Interactions with } \\
\text { biological family \& } \\
\text { caregivers }\end{array}$} & $\begin{array}{l}\text { Family-based out-of- } \\
\text { home care (-) }\end{array}$ \\
\hline & & Biological family $(+/-)$ & & Biological family (+/-) \\
\hline & & Obedience $(+)$ & & $\begin{array}{l}\text { Permission vs. } \\
\text { forbiddance }(+/-)\end{array}$ \\
\hline & & & & Pets $(+)$ \\
\hline & & & & Violence (-) \\
\hline & & & & Life story (-) \\
\hline & \multirow[t]{3}{*}{ Peers } & Friends (+/-) & \multirow[t]{3}{*}{ Peers } & Friends $(+/-)$ \\
\hline & & Competition $(+)$ & & Being in love $(+/-)$ \\
\hline & & Play $(+)$ & & \\
\hline & \multirow[t]{7}{*}{ Appreciation } & (in)justice (-) & \multirow[t]{7}{*}{ Appreciation } & (in)justice (-) \\
\hline & & Punishment (-) & & Shame \& guilt (-) \\
\hline & & $\begin{array}{l}\text { Appreciation of self by } \\
\text { others }(+)\end{array}$ & & $\begin{array}{l}\text { Acceptance vs. } \\
\text { debarment }(+/-)\end{array}$ \\
\hline & & Reputation $(+)$ & & Appearance (+/-) \\
\hline & & & & Attention $(+)$ \\
\hline & & & & Praise vs. critique (+/-) \\
\hline & & & & Win vs. lose $(+/-)$ \\
\hline & \multirow[t]{2}{*}{ Civic life } & $\begin{array}{l}\text { Political } \\
\text { interest/interest in } \\
\text { world affairs (-) }\end{array}$ & \multirow[t]{2}{*}{ Civic life } & $\begin{array}{l}\text { Political } \\
\text { interest/interest in } \\
\text { world affairs (-) }\end{array}$ \\
\hline & & $\begin{array}{l}\text { Celebrating festivals } \\
(+)\end{array}$ & & \\
\hline & Social skills & Empathy $(+)$ & & \\
\hline & & Openness (+) & & \\
\hline & & $\begin{array}{l}\text { Pro-social behaviour } \\
(+)\end{array}$ & & \\
\hline & & & Enjoyment & Pleasure $(+)$ \\
\hline & & & & Celebrations (+) \\
\hline \multirow[t]{14}{*}{ Psychological } & \multirow[t]{7}{*}{ Coping } & Distraction & \multirow[t]{7}{*}{ Coping } & Distraction \\
\hline & & Support by others & & Support by others \\
\hline & & Ventilation & & Ventilation \\
\hline & & Belief & & Thinking \\
\hline & & Nature & & Aggression \\
\hline & & $\begin{array}{l}\text { Pos. reinterpretation \& } \\
\text { growth }\end{array}$ & & \\
\hline & & $\begin{array}{l}\text { Seeking support for } \\
\text { emotional/instrumental } \\
\text { reasons }\end{array}$ & & \\
\hline & $\begin{array}{l}\text { Tsunami-related } \\
\text { symptoms }\end{array}$ & Impact of Tsunami (-) & & \\
\hline & & Memories (-) & & \\
\hline & Nature & $\begin{array}{l}\text { Appreciation of } \\
\text { environment }(+)\end{array}$ & & \\
\hline & & $\begin{array}{l}\text { Appreciation of nature } \\
(+)\end{array}$ & & \\
\hline & & & Leisure & Hobbies $(+)$ \\
\hline & & & & Food $(+/-)$ \\
\hline & & & & Weather $(+/-)$ \\
\hline & & & & \\
\hline & & & & \\
\hline & & & & \\
\hline
\end{tabular}


Table 2 (continued)

\begin{tabular}{|c|c|c|c|c|}
\hline & \multicolumn{2}{|c|}{ Indian sample } & \multicolumn{2}{|c|}{ European sample } \\
\hline Domain & Category & Subcategory & Category & Subcategory \\
\hline \multirow[t]{4}{*}{ Physical } & \multirow[t]{4}{*}{ Health } & $\begin{array}{l}\text { Disaster-related needs } \\
\text { and fears }(-)\end{array}$ & \multirow[t]{4}{*}{ Health } & $\begin{array}{l}\text { Disease/death of } \\
\text { closely related persons } \\
(-)\end{array}$ \\
\hline & & Accident (-) & & \multirow[t]{2}{*}{$\begin{array}{l}\text { Disease/death of own } \\
\text { person (-) }\end{array}$} \\
\hline & & Health $(+/-)$ & & \\
\hline & & Physical activities (+) & & \\
\hline \multirow[t]{2}{*}{ Economic } & \multirow[t]{2}{*}{ Materialism } & Fulfilment of wishes & \multirow[t]{2}{*}{ Materialism } & Fulfilment of wishes \\
\hline & & & & Poverty \\
\hline
\end{tabular}

$(+)$ positive appraisal

(-) negative appraisal

$(+/-)$ positive as well as negative appraisal

category is mentioned by both samples

WIIA

category only exists in either the Indian or European sample

mother]. If I study well, I will buy saree for my mom." In addition to providing children the opportunity to graduate, SOS Children's Villages offered the children chances to participate in different artistic activities, such as singing, drawing, and dancing. The opportunity for artistic expression greatly contributed to the children's well-being: "Here [at SOS Children's Village], there are more activities that develop our skills. Also, I like dance very much here. I get an opportunity to learn dance."

European Children Although the children appreciated school for the opportunity it gave them to make new friends and meet their friends on a regular basis, they generally viewed going to school rather negatively. They reported that they are happy when a school day comes to an end and they can go home because they do not like to study. However, positive school achievements made the children feel good and happy about their skills, whereas their school failures made them feel sad and/or disappointed. Several children stated: "I am happy when I am scoring good marks." Problems with teachers were a source of their unhappiness. For example: "... or when I get a letter of censure from school or something like that, then I know, now I am in trouble ...". Time away from school, such as holidays and weekends, contributed to the children's wellbeing because there was no homework to do and they faced fewer stress factors.

\subsection{Social Domain}

The social domain is concerned with the social environment of a child and ranges from immediate to more distant interactions. Close relationships, the quality of these relationships, and a positive evaluation of the self are central. In addition, interaction with and interest in the wider community are part of this domain.

\subsubsection{Interactions with Biological Families both Support and Threaten Well-Being (Category: Interactions with Biological Family and Caregivers)}

Indian Children Some of the children were orphans, and there was no contact (for different reasons) with their extended family members, which made them feel very sad. 
The majority of the participating children still had a biological family who contributed crucially to their well-being. Even though the children's biological family sometimes did not abide by agreements, which made the children feel very sad, they could overcome their sorrows because their SOS family gave them strength. Within SOS Children's Village, building an attachment with the SOS mother was a significant indicator of well-being. Once this attachment was established, the children enjoyed being with their nuclear (SOS) family, and they could counteract other children who bullied them for being in care. As one child said: "When somebody calls us 'orphan', we turn around and say, 'we are not orphan, we have mother, brother and sister'." In contrast, when children did not become attached to their SOS mother, they tried to become reconciled to their fate and to find positive sides of their life circumstances: "We want to live with mother, father, brother, sister. They died in Tsunami. So we are here [SOS Children's Villages]. Here, we get education, food, and proper clothes." Within these familial relational structures (biological and SOS family), it was important for the children to get and to follow the advice of adults, as it was a clear sign of having somebody who cares for them. They were aware that obedience is essential for a good child-adult relationship.

European Children Similar to the Indian sample, the significance of familial relationships was a fundamental element of the European children's discussions of well-being. Interactions with the biological family were a great source of happiness but were also a source of great unhappiness, almost to the same extent. Although the children spoke a lot about violence as an ill-being indicator in connection with the birth family, the children were longing for contact with them. Meetings with the biological parents were arranged on a regular basis, but they often were disappointing for the children. One child said: “... it makes me sad, my father makes a promise or says something, and then it almost never becomes true. Then I try not to call him anymore, but that doesn't work out, and I call him again. I am very disappointed about that." In general, the children disliked SOS Children's Villages because they could not get used to the fact that they had been separated from their biological family. Living in care was a great source of their ill-being. It was difficult for them to get attached to an SOS caregiver because they were hopeful that they could go back home soon. Consequently, the children tried not to get involved in their care situation, and to some extent, this was why it was very hard for them to accept the SOS caregiver. Nevertheless, SOS caregivers could also be a source of happiness for them: “... when the SOS caregiver says 'yes' to something I really want, or makes an exception, then I really feel good." Only pets, which were counted among the most important relations, exclusively contributed to the children's well-being.

\subsubsection{Positive and Negative Effects of Relationships on the Self (Categories: Peers and Appreciation)}

Indian Children In addition to the significance of family relationships, the children considered friends necessary for their happiness. Friends were not only important to have fun; they were also have like-minded people with whom to share sorrows and joy and allowed the children to act as a confidant for someone 
else. On the one hand, peer interactions were strongly associated with positive feelings of self-worth. The children enjoyed being appreciated by others. On the other hand, peer interactions were a source of great unhappiness. For example, the children quarrelled with their friends and sometimes got excluded from the peer group. As one child put it: "We had a fight. Now she does not speak with me anymore. And my other friends, they don't speak with me either." Family relationships (biological and SOS) also contributed positively and negatively to the children's self-worth. In particular, getting scolded and punished by caregivers or family members triggered feelings of injustice and had a negative impact on the children's self-worth because they tried so hard to pave the way for a better future for themselves and their family (see 5.1.1 category: academic). However, harmonious relationships were crucial for children's well-being.

European Children Having friends and being with friends were great sources of the children's happiness. "... When I spend time with my friends, then I feel good, because then I am with my friends and I can do something with them that I like." However, friendships can also be very hurtful and can make children feel unhappy; for example, "... sometimes my friend, she exploits my special trust and that makes me feel so sad, and it makes me angry as well ...". In particular, exclusion from one's peer group was a great source of ill-being because feelings of self-worth were anchored in experiences of positive recognition and in feeling a sense of belonging. Positive recognition was obtained either formally (e.g., winning a trophy at a soccer game) or informally (e.g., getting praised). In general, ill-being was mainly caused by arguments and problems with important others, which in turn was partly perceived as an attack against the self. In addition, significant others served important roles in the children's lives by giving attention, showing appreciation, and being points of reference for assessing how they were doing. The following example illustrates how a child enjoyed the undivided attention of a caregiver: "When I do something with the [SOS] caregiver, just me and him, nobody else, then I really feel good."

\subsubsection{Indian and European Children Name Different Exclusive Well-Being Sources (Categories: Social Skills/Indian Children and Enjoyment/European Children)}

Indian Children - Social Skills As mentioned above, the children primarily defined happiness as a condition of relational harmony. They consciously put great effort into preserving this harmony through their social skills. It made them happy to be available for somebody who needed their help or support. Being empathetic with others was also a source of their happiness. For example, "If they [friends] smile and feel happy, and me, I also feel happy then." Another feature of the children's social skills was their openness towards others and, in general, towards everything that was new to them. With their sincere interest, they expressed their appreciation of unfamiliar others and new things and situations.

European Children - Enjoyment The children reported that 'having fun' and celebrating birthdays and Christmas were sources of their happiness. 'Having fun' was closely linked to 'hanging out' with friends and doing nothing special. However, 
engaging in activities that the children were good at also counted among this category. The main characteristic of 'having fun' was that the children have a stress-free time.

\subsection{Psychological Domain}

The core of this domain is mental health and its preservation or prevention through the handling of distressing situations.

\subsubsection{Cross-Cultural and Culture-Specific Coping and Relaxation Strategies (Categories: Coping, Tsunami-Related Symptoms, Nature, Leisure)}

Indian Children The children described their ability to cope with adverse circumstances. The presence of supportive, caring others was important for helping them deal with a variety of difficulties. They either shared their feelings and thoughts with others or sought advice, assistance or information from them. They also tried to overcome their sorrows without the help of others through their beliefs, distraction, reflecting on their own mistakes and venting.

Noticeable was the importance of 'nature' to their well-being. The children not only highly appreciated the beauty of nature but also valued its calming and comforting effect in times of sorrow. Taking about this issue, one child said: "When I feel sad, I look at flowers. In those flowers, I am able to see my father's face. He loved flowers. Also, I am able to see my relatives' face, so I like flowers. And clouds. After the funeral of my father, they made many flowers in that place [...]." In addition, the children recognised that nature is a treasure that needs to be conserved. They reported that preserving nature and taking care of the environment gives them happiness ("If plants or leaves become dry then I feel sad. Because trees help us in many ways; they give medicine, fruit, etc."), whereas Tsunami-related issues, such as memories of Tsunami and the negative impact it had on their lives, were strong sources of their ill-being, even four years post-disaster.

European Children To a certain extent, the European children named coping strategies similar to those of the Indian children. One of the most popular coping strategies was distraction. They tried to take their minds off their sorrows via friends ("Most of the time, I go to the movies with a friend or something like that."), family, pets ("... or I huddle up to my dog"), hobbies, and food (“... just eating sweets."). They also released their tensions and emotions (e.g., crying and feeling better afterwards) to cope with adversities. Another form of releasing built-up emotions was aggressive behaviour (" $I$ bang the door, I kick at the door, I scold others and use swear words"). Some of the children coped with adverse situations by facing up to the problem. The children actively sought support from others, such as friends, family, and caregivers, or they thought about their sorrows and tried to find a way out by themselves.

Leisure time as a source of well-being was only named by the European children. Leisure time differed from being off school as it was in no way connected to school. Hobbies, such as playing computer games and listening to music contributed exclusively to the children's happiness, whereas food and weather could also be a source of ill-being for the children when they differed from the children's ideas of how they 
should be. In general, favourite dishes and sweets made the children feel happy. As one child said: "... eating my favourite food, like cheese fondue, makes me happy." Additionally, warm and sunny weather affected the children's well-being: "... because today, the sun is shining, it's a beautiful day... it was raining the last few days, but now, it's warm."

\subsection{Physical Domain}

The physical domain comprises physical health and the preservation of a healthy physical state.

\subsubsection{Staying Physically Healthy Is Important to the Children's Well-Being (Category: Health)}

Indian Children The children distinguished disasters, accidents, health, and physical activities as sources of ill-being and well-being. Although the Tsunami occurred four years ago, the children had vivid memories of the disaster and the injuries involved that were linked with extreme feelings of ill-being. The Tsunami not only caused immense physical impairments to the children themselves and to others but was responsible for losses from which the children continued to suffer. The majority of the children mentioned the death of their family members: "Because of Tsunami, all my family members died, such as our dad, mom, siblings. That makes us sad." As the children knew only too well what it meant to face a threat to their own and others' life, they greatly appreciated the state of a healthy body. Hence, they knew about the importance of staying physically healthy. They said that good health enables them to be physically active, and the enjoyment of physical activities definitely contributed to their wellbeing.

European Children The children mentioned the absence of health and the possibility of dying as ill-being indicators. Disease and the death of close relatives as well as experiencing disease and possible death of themselves made the children feel sad. As one child put it: "When a person who is important to me is ill, I also feel bad." Additionally, the death of many people, as in the case of a natural disaster, for example, was a source of their unhappiness.

\subsection{Economic Domain}

In this domain, the children focused on material resources that meet their basic needs and beyond.

\subsubsection{Material and Economic Resources Are Clearly Linked with children's Well-Being} (Category: Materialism)

Indian Children The children clearly established a link between material resources and well-being. They greatly appreciated that the SOS family had enough money to 
provide a decent standard of living for them. Moreover, not only their basic needs but also their wishes beyond their basic needs could be fulfilled. One child said: "We didn't get food. After we came here [SOS Children's Village], we are fine. Whatever we want, our mom [SOS mother] will get for us. Our mom is treating us well." From their discussions, it was obvious that the children know all too well what it means to live in poverty, as their families of origin were very poor. They reported that due to their bad economic circumstances before the Tsunami, they were experienced some social exclusion.

European Children Like the Indian children, the European children unambiguously linked money and well-being. Pocket money that was freely available to them made them feel happy. As several children said: “... I can go shopping with my own money. I like shopping." Thus, material resources in the form of money and presents contributed to the children's well-being. However, the children also discussed what it is like to live in poverty and how not having economic prosperity made them feel extremely sad. They were not only concerned about their own experience of poverty but also about other poor people: "... it is so bad when one knows that he does not have a good life, when he has to live on the street or something like that, I don't know...".

\section{Discussion}

The present study attempted to uncover an understanding of well-being from a child's perspective. A major focus of this study was how culture (European/Western vs. Indian/ Eastern cultural background) might influence the viewpoints that children in care have regarding their own well-being. By comparing the results of two culturally different groups, the study reveals three key aspects related to cultural impact. In general, the children identified (1) similar global sources of their happiness but with differences in the meaning of the individual themes; (2) well-known culture-specific well-being themes; and (3) not well-known culture-specific well-being themes (Indian children). Specifically, seven main themes were formulated: 'Indian and European children attach different values to school', 'interactions with biological families both support and threaten well-being', 'positive and negative effects of relationships on the self', 'Indian and European children name different exclusive well-being sources', 'cross-cultural and culture-specific coping and relaxation strategies', 'staying physically healthy is important to the children's well-being', and 'material and economic resources are clearly linked with children's well-being'.

We found that the majority of children, regardless of their cultural background, mentioned more or less identical themes of well-being: 'academic', 'appreciation', 'interaction with biological family and caregivers', 'peers', 'coping', 'health', and 'materialism'. Children from a Western cultural background commonly bring up these themes, as shown by Dex and Hollingworth (2012), who reviewed the literature on children's voices regarding their well-being. It can be assumed that in these studies, the meaning of the themes was more or less similar. In the context of cultural influences on children's views regarding their own well-being, our results suggest that the meaning of the themes is shaped by a child's mode of being; that is, according to Markus and 
Kitayama (1991, 2003), either an independent or interdependent self-construal. The former is dominant in Western cultures and focuses on mental states and personal qualities that support self-expression and self-maximisation (ibid.). For example, 'academic success' for most of the European children meant mainly positive, formal recognition of those who do well. A similar result was found in Fattore et al.'s (2009) study with Australian child informants, who named rewards within an educational context as a part of a positive sense of self. The findings of Fattore et al. (2009) and our study indicate that 'academic success' refers to the recognition of a personal attainment that leads to self-enhancement and consequently contributes to a child's happiness. In contrast, connectedness with others was a priority for almost all the Indian children because they held an interdependent view of the self. In this sense, they viewed 'academic success' as a step closer to their wish to succeed in order to support their family of origin and look after their own (future) family in a proper way. The theme 'appreciation' is another example of our data that emphasises the two divergent aspects of the self in relation to children's views of what constitutes well-being. Although both groups of children mentioned that being appreciated by others gives them happiness, the majority of the European children stressed the appreciation of their uniqueness (e.g., appearance) and the importance of asserting their self. Any appreciation, such as praise, winning a game, or getting special attention, was viewed as beneficial to well-being, whereas being criticised was viewed rather negatively, i.e., as an attack on the child's personality. In contrast, many of the Indian children perceived critiques positively because they felt that getting and following the advice of adults helped them to improve their own reputation. Moreover, following the advice of elders is also related to respect and obedience, which is the core of group harmony in collectivist cultures (Greenfield et al. 2003; Tamis-LeMonda et al. 2008) and was also highly valued in the Indian sample. Some of the Indian children positively mentioned obedience in connection with family-based out-of-home care life because it stands for harmony, and a harmonious family life is an indicator of well-being. Almost all the European children had issues with a caregiver regarding getting what they wanted, i.e., it was hard for them to accept a ban and consequently show their anger. As previously mentioned, anger considered an ego-focused emotion, and these are more frequently expressed by people with independent selves (Markus and Kitayama 1991). Generally, the meanings of the Indian children's well-being themes were more relational and interdependence oriented, whereas self-determination was the underlying meaning of the European children's well-being themes. However, our data also show that certain sources of happiness and the general meaning of happiness as a state of positive feeling about oneself seem to be universally accepted. Not surprising was the prominence of successful relationships in different contexts (e.g., school, family, peer groups) for the Indian and European children's well-being. This finding is in line with the results of Delle Fave et al. (2011), who specifically investigated how adults from seven different countries define happiness and what things adults consider most meaningful. The researchers found that the importance of relationships stands out among the contexts of happiness and among the most meaningful things.

The second set of findings refers to the identification of well-known, culture-specific well-being themes. 'Enjoyment' and 'leisure' count among the well-known culturespecific themes and were mentioned only by the European children, and almost the entire European sample mentioned these themes. It is not surprising that the European 
children mentioned 'pure' enjoyment as a source of their well-being given that the dominant view of happiness in Western cultures is basically hedonic (Joshanloo 2014). Another core value in Western cultures is personal choice. This value originates from an individualist parenting style that encourages children to develop into independent and autonomous individuals (Tamis-LeMonda et al. 2008). In relation to the theme 'leisure', this implies that the children are not only allowed to keep their own schedule during their leisure time but also that they are allowed to choose their hobbies according to their interests. Iyengar and Lepper (1999) found in their studies with children aged 7 to 10 years that the provision of individual choice seems to be crucial to children with the cultural notion of independent selves. The act of making a personal choice provides opportunities for both the expression of personal preferences and the chance to establish a unique self-identity. According to Dambrun and Ricard (2011), the key ingredients of happiness in Western societies stand out because of the extreme sense of importance given to the self. In contrast to the self-centredness found in Western cultures, selflessness characterises people from Eastern cultures (Dambrun and Ricard 2011). In this sense, some of the Indian children mentioned 'social skills' as a well-known culture-specific well-being theme. Dambrun and Ricard (2011) argue that a less-selfish conceptualisation of happiness can lead to greater frequencies of empathy, respect, and other qualities that are signifiers of psychological maturity and good indicators for well-being in Eastern cultures.

Finally, a very striking result was the importance of nature for all the Indian children (see also Exenberger and Juen 2014). The content of 'nature' resembles the category 'harmony/balance' in Delle Fave et al.'s cross-country study mentioned above. The term reflects the perception of harmony at the inner level as inner peace, self-acceptance, and serenity. According to the authors, this feeling of balance and evenness is best framed by philosophical traditions in Asian cultures. One might assume that this kind of philosophy is so deeply rooted in individuals belonging to Eastern cultures that it made even our young participants aware of the calming effect of beauty in nature. Looking at a beautiful flower or the shape of the clouds helped the children gain inner peace and overcome their sorrows. Nature itself was highly valued by the children, on the one hand as source for relaxation, on the other hand for clearing the mind. Moreover, the beauty of nature helped the children to create their own inner private psychological space to which they could retreat for a few moments to regain their strength. This inner self is a highly protected reservoir for inner needs and ambitions and allows people to become individuated (Sinha et al. 2001) in a collectivist surrounding. After experiencing such reinvigoration, the children remarked that they wished to share their good spirit with others by making them, for example, flower presents. The desire to bring joy to others (e.g., with flower presents) is another expression of an interdependent self that is characterised by having strong feelings of connectedness with others (Markus and Kitayama 1991, 2003).

In addition to the newly identified well-being theme 'nature', all the Indian children also mentioned an ill-being theme called 'Tsunami-related symptoms'. Given that wellbeing is not only grounded in a particular place or geographical region but also in a particular time (Triandis 1996; White 2008), this ill-being theme emerged because of its strong relation to the timing of the questioning (four years post-Tsunami). Hence, on a more abstract level, circumstances and not just within-person factors should always be considered when assessing children's well-being. 
Limitations of the study include the fact that the members of one group had experienced comparable trauma (the Tsunami), whereas the members of the other group had not. This is evident in some of the findings, namely, the Tsunami-related symptoms as an ill-being factor in the Indian sample and the core family as an ill-being factor in the European sample. For these domains, we cannot assess the cultural impact. It would be interesting to study children who have experienced trauma in the family in different cultures and/or children who have experienced a natural disaster in different cultures. Another limitation lies in the small sample sizes, which do not allow for generalisations but offer possible directions for further investigating culture-specific well-being indicators in children.

Nevertheless, in conclusion, this study demonstrates two global findings regarding children's happiness from their own perspective: (1) the sources of children's happiness or SWB may be universal, but the meaning of happiness seems to be culture-bound, and (2) the children are aware of the dual focus on well-being and ill-being. The first main finding is in line with what is known from adult samples. Similar to the findings of Lu and Gilmour (2006) with adults, children with an interdependent self (according to the definition of Markus and Kitayama 1991) differ in their conception of happiness from children with an independent self in that the former have a more social-oriented conception of happiness, while the latter have a more individual-oriented one. However, different scholars (e.g., Guisinger and Blatt 1994; Triandis 1995) speak of the dual aspects of human nature, i.e., that tendencies towards individuality and relatedness exist in every individual. Additionally, the second main finding, which highlights the dialectical view of SWB, is not totally novel and is in agreement with various study results (e.g., Lu and Gilmour 2004, 2006). Lu and Gilmour (2004) noted that this dialectic may imply some ambivalence towards happiness because happiness can also be defined from the opposite perspective of not having something bad or undesirable happen. Although this 'negative' view of happiness was present in both samples of children, a slight difference in the children's view of the relationship between happiness and unhappiness could be assumed. To put it carefully, it seemed that the Indian children were able to more easily accept the 'negative side of the coin' and find something positive in a negative event. For example, the Western children almost consistently viewed their stay at a family-based out-of-home care negatively. It is possible that their hope of returning to live with their biological family hindered their attachment to SOS caregivers. In contrast, the Eastern children (even those who could not become attached to their SOS mother) tried to view their situation positively. These different ways of thinking could originate from ancient cultural traditions that imply that the Western mindset is characterised by linear and analytic thinking styles, whereas the Eastern mindset is shaped by cyclical reasoning (Ji et al. 2001).

From the direct comparisons of the Eastern and Western children's conceptions of happiness, it could be cautiously assumed that the children's concepts of well-being are deeply rooted in their culture of origin. Thus, cultural traditions in general, and in particular Eastern and Western traditions, should be taken into account when discussing well-being and its indicators.

Acknowledgments Open access funding provided by University of Innsbruck and Medical University of Innsbruck. The research leading to these results has received funding from the European Community's Seventh Framework Programme FP7-PEOPLE-2007-4-1-IOF, Marie Curie Actions - International Outgoing Fellowships (IOF) under grant agreement no. 220535 (Silvia Exenberger). 
Open Access This article is distributed under the terms of the Creative Commons Attribution 4.0 International License (http://creativecommons.org/licenses/by/4.0/), which permits unrestricted use, distribution, and reproduction in any medium, provided you give appropriate credit to the original author(s) and the source, provide a link to the Creative Commons license, and indicate if changes were made.

\section{References}

Andresen, S., \& Fegter, S. (2011). Children growing up in poverty and their ideas on what constitutes a good life: Childhood studies in Germany. Child Indicators Research, 4(1), 1-19. https://doi.org/10.1007 /s12187-010-9073-3.

Bavinck, M. (2008). Collective strategies and windfall catches: Fisher responses to tsunami relief efforts in South India. Transforming Cultures eJournal, 3. http://epress.lib.uts.edu.au/journals/index. php/TfC/article/view/923. Accessed 10 Nov 2017.

Ben-Arieh, A. (2005). Where are the children? Children's role in measuring and monitoring their well-being. Social Indicators Research, 74(3), 573-596. https://doi.org/10.1007/s11205-004-4645-6.

Ben-Arieh, A. (2008). The child indicators movement: Past, present, and future. Child Indicators Research, 1(1), 3-16. https://doi.org/10.1007/s12187-007-9003-1.

Ben-Arieh, A. (2010). Developing indicators for child well-being in a changing context. In C. McAuley \& W. Rose (Eds.), Child well-being. Understanding children's lives (pp. 129-142). London, Philadelphia: Jessica Kingsley Publishers.

Boyden, J., \& Ennew, J. (1997). Children in focus - A manual for participatory research with children. Save the Children Sweden. https://www.unicef.org/videoaudio/PDFs/Children-in-Focus.pdf. Accessed 10 Nov 2017.

Bradshaw, J., Hoelscher, P., \& Richardson, D. (2007). An index of child well-being in the European Union. Social Indicators Research, 80(1), 133-177. https://doi.org/10.1007/s11205-006-9024-Z.

Camfield, L., Streuli, N., \& Woodhead, M. (2008). Children's well-being in contexts of poverty: Approaches to research, Monitoring and Participation. Young Lives. http://oro.open.ac.uk/16990/1/TN12ChildWellBeing.pdf. Accessed 10 Nov 2017.

Caritas Kinderdorf Irschenberg (n.d.). Kinderdorf Irschenberg. https://www.caritas-nah-am-naechsten. de/Kinderdoerfer/Kinderdorf-Irschenberg/default.aspx. Accessed 10 Nov 2017.

Corbin, J., \& Strauss, A. (2008). Basics of qualitative research (3rd ed.). London: Sage Publications.

Dambrun, M., \& Ricard, M. (2011). Self-centeredness and selflessness: A theory of self-based psychological functioning and its consequences for happiness. Review of General Psychology, 15(2), 138-157. https://doi.org/10.1037/a0023059.

Deci, E. L., \& Ryan, R. M. (2008). Hedonia, eudaimonia, and well-being: An introduction. Journal of Happiness Studies, 9(1), 1-11. https://doi.org/10.1007/s10902-006-9018-1.

Delle Fave, A., Brdar, I., Freire, T., Vella-Brodrick, D., \& Wissing, M. P. (2011). The eudaimonic and hedonic components of happiness: Qualitative and quantitative findings. Social Indicators Research, 100(2), 185207. https://doi.org/10.1007/s11205-010-9632-5.

Dex, S., \& Hollingworth, K. (2012). Children's and young people's voices on their well-being. Childhood well-being research Centre, working paper 16. https:/www.gov.uk/government/uploads/system/uploads/attachment_ data/file/181515/CWRC-00108-2012.pdf. Accessed 10 Nov 2017.

Diener, E. (1984). Subjective well-being. Psychological Bulletin, 95(3), 542-575.

Diener, E., \& Napa Scollon, C. (2014). The what, why, when, and how of teaching the science of subjective well-being. Teaching of Psychology, 41(2), 175-183. https://doi.org/10.1177/009862831453034675-183.

Diener, E., \& Suh, E. M. (2000). Measuring subjective well-being to compare the quality of life of cultures. In E. Diener \& E. M. Suh (Eds.), Culture and subjective well-being (pp. 3-12). Cambridge: MIT Press.

Diener, E., Diener, M., \& Diener, C. (1995). Factor predicting the subjective well-being of nations. Journal of Personality and Social Psychology, 69(5), 851-864.

Diener, E., Suh, E., \& Oishi, S. (1997). Recent findings on subjective well-being. Indian Journal of Clinical Psychology, 24(1), 25-41.

Dinisman, T., Fernandes, L., \& Main, G. (2015). Findings from the first wave of the ISCWeB project: International perspectives on child subjective well-being. Child Indicators Research, 8(1), 1-4. https://doi.org/10.1007/s12187-015-9305-7. 
Exenberger, S. (2013). Case study 3: The work with interpreters in a cultural-sensitive environment. In A. Graham, M. Powell, N. Taylor, D. Anderson, \& R. Fitzgerald (Eds.), Ethical research involving children (pp. 120-121). Florence: UNICEF Office of Research - Innocenti.

Exenberger, S., \& Juen, B. (2014). Well-being, resilience and quality of life from children's perspectives: A contextualized approach. Dordrecht: Springer Briefs.

Fattore, F., Mason, J., \& Watson, E. (2007). Children's conceptualization(s) of their well-being. Social Indicators Research, 80(1), 5-29. https://doi.org/10.1007/s11205-006-9019-9.

Fattore, F., Mason, J., \& Watson, E. (2009). When children are asked about their well-being: Towards a framework for guiding policy. Child Indicators Research, 2(1), 57-77. https://doi.org/10.1007/s12187008-9025-3.

Fernandes, L., Mendes, A., \& Teixeira, A. A. C. (2012). A review essay on the measurement of child wellbeing. Social Indicators Research, 106(2), 239-257. https://doi.org/10.1007/s11205-011-9814-9.

Gabhainn, S. N., \& Sixsmith, J. (2005). Children's understanding of well-being. Centre for Health Promotion Studies, National University of Ireland. http://www.dcya.gov.ie/documents/research/childrenunderstandingofwellbeing.pdf. Accessed 10 Nov 2017.

Glaser, B., \& Strauss, A. (1967). The discovery of grounded theory. Chicago: Aldine.

Greenfield, P. M., Keller, H., Fuligni, A., \& Maynard, A. (2003). Cultural pathways through universal development. Annual Review of Psychology, 54, 461-490. https://doi.org/10.1146/annurev. psych.54.101601.145221.

Guisinger, S., \& Blatt, S. J. (1994). Individuality and relatedness. Evolution of a fundamental dialectic. American Psychologist, 49(2), 104-111.

Huebner, E. S. (2004). Research on assessment of life satisfaction of children and adolescents. Social Indicators Research, 66(1), 3-33. https://doi.org/10.1023/B:SOCI.0000007497.57754.e3.

Iyengar, S. S., \& Lepper, M. R. (1999). Rethinking the value of choice. A cultural perspective on intrinsic motivation. Journal of Personality and Social Psychology, 76(3), 349-366.

Ji, L., Nisbett, R. E., \& Su, Y. (2001). Culture, change, and prediction. Psychological Science, 12(6), 450-456.

Joshanloo, M. (2014). Eastern conceptualizations of happiness: Fundamental differences with western views. Journal of Happiness Studies, 15(2), 475-493. https://doi.org/10.1007/s10902-013-9431-1.

Land, K. C., Lamb, V. L., \& Zheng, H. (2011). How are the kids doing? How do we know? Recent trends in child and youth well-being in the United States and some international comparisons. Social Indicators Research, 100(3), 463-477. https://doi.org/10.1007/s11205-010-9624-5.

Lu, L. (2001). Understanding happiness: A look into the Chinese folk psychology. Journal of Happiness Studies, 2(4), 407-432.

Lu, L., \& Gilmour, R. (2004). Culture and concepts of happiness: Individual oriented and social oriented SWB. Journal of Happiness Studies, 5(3), 269-291.

Lu, L., \& Gilmour, R. (2006). Individual-oriented and socially oriented cultural conceptions of subjective well-being: Conceptual analysis and scale development. Asian Journal of Social Psychology, 9(1), 36-49. https://doi.org/10.1111/j.1367-2223.2006.00183.x.

Markus, H. R., \& Kitayama, S. (1991). Culture and the self: Implications for cognition, emotion and motivation. Psychological Review, 98(2), 224-253.

Markus, H. R., \& Kitayama, S. (2003). Culture, self, and the reality of the social. Psychological Inquiry, 14(3\&4), 277-283.

Newland, L. A., Lawler, M. J., Giger, J. T., Roh, S., \& Carr, E. R. (2015). Predictors of Children's subjective well-being in rural communities of the United States. Child Indicators Research, 8(1), 177-198. https://doi.org/10.1007/s12187-014-9287-x.

O'Hare, W. P. (2012). Development of the child indicator movement in the United States. Child Development Perspectives, 6(1), 79-84. https://doi.org/10.1111/j.1750-8606.2011.00214.x.

Pflug, J. (2009). Folk theories of happiness: A cross-cultural comparison on conceptions of happiness in Germany and South Africa. Social Indicators Research, 92(3), 551-563. https://doi.org/10.1007/s11205008-9306-8.

Pollard, E. L., \& Lee, P. D. (2003). Child well-being: A systematic review of the literature. Social Indicators Research, 61(1), 59-78.

Rees, G., Goswami, H., Pople, L., Bradshaw, J., \& Keung, A. (2013). The good childhood report 2013. The Children's Society and the University of York. https:/www.childrenssociety.org.uk/sites/default/files/tcs/good_ childhood_report_2013_final.pdf.

Ryan, R. M., \& Deci, E. L. (2001). On happiness and human potentials: A review of research on hedonic and eudaimonic well-being. Annual Review of Psychology, 52, 141-166.

Ryff, C. D. (1989). Happiness is everything, or is it? Explorations on the meaning of psychological well-being. Journal of Personality and Social Psychology, 57(6), 1069-1081. 
Ryff, C. D., \& Singer, B. (1998). The contours of positive human health. Psychological Inquiry, 9(1), 1-28. Sinha, J. B. P., Sinha, T. N., Verma, J., \& Sinha, R. B. N. (2001). Collectivism coexisting with individualism: An Indian scenario. Asian Journal of Social Psychology, 4(2), 133-145.

SOS Children's Villages: A general overview. (n.d.). https:/www.sos-childrensvillages.org/getmedia/4321 dda1-1db7-4275-a511-d21d3fcdf9cb/Programme-Policy-en-small.pdf?ext=.pdf. Accessed 10 Nov 2017.

Suh, E. M. (2000). Self, the hyphen between culture and subjective well-being. In E. Diener \& E. M. Suh (Eds.), Culture and subjective well-being (pp. 63-86). Cambridge: The MIT Press.

Tamis-LeMonda, C. S., Way, N., Hughes, D., Yoshikawa, H., Kalman, R. K., \& Niwa, E. Y. (2008). Parents' goals for children: The dynamic coexistence of individualism and collectivism in cultures and individuals. Social Development, 17(1), 183-209. https://doi.org/10.1111/j.1467-9507.2007.00419.x.

Tov, W., \& Diener, E. (2013). Subjective well-being. In K. D. Keith (Ed.), The encyclopedia of cross-cultural psychology. Wiley-Blackwell: Maulden.

Triandis, H. C. (1995). Individualism \& Collectivism. Boulder: Westview Press.

Triandis, H. C. (1996). The psychological measurement of cultural syndromes. American Psychologist, 51(4), 407-415.

Uchida, Y., Norasakkunkit, V., \& Kitayama, S. (2004). Cultural constructions of happiness: Theory and empirical evidence. Journal of Happiness Studies, 5(3), 223-239.

UNICEF (n.d.). Rights under the Convention on the Rights of the Child - Participation Rights. https://www. unicef.org/crc/files/Participation.pdf. Accessed 10 Nov 2017.

Vogl, S. (2005). Gruppendiskussion mit Kindern: Methodische und methodologische Besonderheiten. In: Zentralarchiv für Empirische Sozialforschung (Ed.), ZA-information 57 (pp. 28-60). Köln: Universität zu Köln.

White, S. (2008) But What is Well-being? A Framework for Analysis in Social and Development Policy and Practice, WeD Working Paper 43. http://staff.bath.ac.uk/ecsscw/But_what_is_Wellbeing.pdf. Accessed 10 Nov 2017.

Wilmes, J., \& Andresen, S. (2015). What does "good childhood" in a comparative perspective mean? An explorative comparison of child well-being in Nepal and Germany. Child Indicators Research, 8(1), 3347. https://doi.org/10.1007/s12187-014-9292-0. 